\title{
IUPAC 2017 NO BRASIL: UMA CONQUISTA HISTÓRICA
}

Em 2017, o Brasil irá receber mais um grande evento internacional, três anos depois da Copa do Mundo e um ano após a realização dos Jogos Olímpicos. O Brasil foi escolhido como país-sede do $46^{\circ}$ Congresso Mundial de Química e $49^{\mathrm{a}}$ Assembleia Geral da União Internacional de Química Pura e Aplicada (IUPAC, da sigla inglesa para Internacional Union of Pure and Applied Chemistry). Diversos fatores contribuíram para a concretização de uma das maiores aspirações da comunidade científica brasileira, que foi aprovada durante a $47^{\mathrm{a}}$ Assembleia Geral da IUPAC em 14 de agosto de 2013 em Istambul, na Turquia. Nesta oportunidade, a delegação brasileira venceu a disputa com a Austrália para sediar o congresso, que é considerado o maior e mais importante evento de Ciências Químicas do mundo. Estiveram presentes, representando nossa Sociedade neste momento histórico, os professores Vitor F. Ferreira (UFF, presidente da SBQ), Adriano D. Andricopulo (USP, presidente sucessor da SBQ e presidente do Comitê de Candidatura da IUPAC no Brasil), Fernando Galembeck (LNNano/CNPEM e Unicamp, ex-presidente e membro do Conselho Consultivo da SBQ), Vanderlan da S. Bolzani (UNESP, ex-presidente e membro do Conselho Consultivo da SBQ), Jailson B. de Andrade (UFBA, ex-presidente e membro do Conselho Consultivo da SBQ), Luiz Henrique Catalani (USP, membro do Conselho Consultivo da SBQ) e Aldo José Gorgatti Zarbin (UFPR, secretário geral da SBQ).

As ações da SBQ para a realização da IUPAC 2017 foram iniciadas em 2010 sob a coordenação do professor César Zucco, então presidente da SBQ. Os objetivos sempre foram claros e bem definidos na busca do desenvolvimento e fortalecimento da Química no país, com contribuições significativas em diversos aspectos para toda a América do Sul. O caminho foi longo e as muitas dificuldades e obstáculos foram vencidos com coragem e determinação. A primeira etapa do processo envolveu o registro da proposta de candidatura do Brasil, que foi julgado e aprovado pelo Conselho da IUPAC, em 2012. No início de 2013 foram disponibilizados o site (http://www.sbq.org.br/IUPAC2017) e o vídeo oficial (http:// www.youtube.com/watch?v=-2H3y56w-2A\&feature=youtu.be) de nossa candidatura. Especialmente desenvolvidos para esta finalidade, o site e o vídeo demonstram a qualidade e seriedade do trabalho com que pretendemos sediar os eventos máximos da IUPAC. A estrutura da candidatura do Brasil se consolidou em pilares sólidos, fundamentados em aspectos científicos, sociais e históricos, que foram amplamente reconhecidos pela comunidade química de todos os continentes, representada na Assembleia Geral da IUPAC. Com um planejamento estratégico e com execução eficaz fomos capazes de conquistar o respeito e o apoio internacional necessários para o sucesso de nossa empreitada.

Em quase 100 anos de existência será a primeira vez que o continente sulamericano sediará o evento, que, portanto, terá importância histórica. A América do Sul e, consequentemente, o Brasil já têm seus lugares garantidos no mapa mundial da Química, contribuindo para a consolidação de uma das principais ações de longo prazo da SBQ. Este processo de internacionaliza- ção se intensificará ainda mais nos próximos anos, com a realização dos principais eventos da IUPAC 2017. Estamos abrindo portas, aproveitando oportunidades em novos patamares, multiplicando canais de comunicação e escrevendo novos capítulos da nossa história, com ética, consciência e sabedoria.

A inserção da Química brasileira no cenário internacional tem mudado muito nas últimas décadas. Cada vez mais cientistas brasileiros colaboram expressivamente para o conhecimento global e suas contribuições são percebidas e reconhecidas. Estudantes brasileiros no exterior são frequentemente elogiados pelos seus orientadores e supervisores, que os comparam favoravelmente a outros jovens. A indústria química brasileira, especialmente algumas notáveis empresas nacionais, figura com destaque nas estatísticas globais.

Em aproximadamente quatro anos, o Brasil receberá o mais global de todos os eventos da Química em um cenário diferente do que era observado há cerca de 30 anos. O mundo reconhece, hoje, que as soluções dos grandes problemas globais passam pela Química e, mais do que então, esta ciência é valorizada por todos os que trabalham por vidas mais significativas, dignas e prazerosas para o maior número possível de pessoas em todas as regiões geográficas do planeta. Apesar de todas as incertezas, podemos esperar que a grande celebração da Química no país se dará em um momento positivo para essa área, no Brasil e no mundo. Cabe ainda destacar que em 2017 a SBQ completará 40 anos de sua fundação e não faltarão motivos para celebrarmos com muita alegria esta ocasião tão especial. O congresso da IUPAC e a $40^{\text {a }}$ Reunião Anual da SBQ serão uma oportunidade única de congregar jovens estudantes de todos os continentes e dos mais diversos níveis, além de um número expressivo de profissionais da academia e da indústria, entre professores e pesquisadores seniores e juniores.

Em 2017, São Paulo será a capital mundial da Química. A partir de agora, os desafios serão ainda maiores, bem como as oportunidades para construirmos um lindo capítulo na história da Ciência brasileira. Não será uma tarefa simples, mas a SBQ está preparada e confiante na sua força e no poder de união de nossa comunidade para alcançar pleno êxito nesta empreitada grandiosa. É necessário explorar positivamente este panorama favorável para darmos um grande salto de qualidade científica, humana e tecnológica, compartilhando nosso entusiasmo pela Química e pelo futuro de nossa nação. Trabalharemos com planejamento, organização, dedicação e eficiência para realizar um evento à altura da confiança depositada em nós pela comunidade química mundial.

Agradecemos e esperamos continuar contando com o apoio e a colaboração de todos!

Adriano D. Andricopulo Fernando Galembeck Vitor F. Ferreira 


\section{química nova}

Química Nova publica artigos com resultados originais de pesquisa, trabalhos de revisão, divulgação de novos métodos ou técnicas, educação e assuntos gerais, em português, inglês e espanhol. Os artigos submetidos à revista são avaliados por consultores ad hoc (do Brasil e do exterior) especialistas na área envolvida e que, eventualmente, podem pertencer ao Conselho Editorial. A edição de Química Nova está a cargo de um corpo editorial e suas linhas gerais e planejamento de longo prazo estão sob responsabilidade dos Editores e do Conselho Editorial. Química Nova publica 10 fascículos por ano.

A versão on line está disponível em:

http://quimicanova.sbq.org.br/quimicanova.htm

Indexação: Chemical Abstracts, ISI e SciELO.

\section{Editores}

Luiz Henrique Catalani (USP)

Susana I. C. de Torresi (USP)

Vera L. Pardini (USP)

\section{Editores Associados}

Aldo J. G. Zarbin (UFPR)

Débora de A. Azevedo (UFRJ)

Jorge M. David (UFBA)

Marco T. Grassi (UFPR)

Renato S. Freire (USP)

Rochel M. Lago (UFMG)

Gerente Editorial

Ursula Brocksom

\author{
Conselho Editorial \\ Damià Barceló (Espanha) \\ Denise F. S. Petri (IQ/USP) \\ Ernesto Calvo (Argentina) \\ Glaura G. Silva (UFMG) \\ Hector Mansilla (Chile) \\ Heloise O. Pastore (UNICAMP) \\ Jorge Calderon (Colômbia) \\ José A. da S. Cavaleiro (Portugal) \\ Julio C. Afonso (UFRJ) \\ Luiz Lopes (UFC) \\ Marcus M. Sá (UFSC) \\ Nelson H. Morgon (UNICAMP) \\ Roberto Faria (UFRJ) \\ Salete L. Queiroz (IQSC/USP) \\ Silvio do D. Cunha (UFBA)
}

\section{SOCIEDADE BRASILEIRA DE QUÍMICA}

\section{Diretoria}

Presidente: Vitor Francisco Ferreira (UFF)

Presidente Sucessor: Adriano D. Andricopulo (IFSC-USP)

Vice-Presidente: Claudia Moraes de Rezende (UFRJ)

Secretário Geral: Aldo José Gorgatti Zarbin (UFPR)

Secretário Adjunto: Luiz Fernando da Silva Jr. (IQUSP)

Tesoureira: Rossimiriam Pereira de Freitas (UFMG)

Tesoureiro Adjunto: Carlos Alberto Manssour Fraga (UFRJ)

Diretora Executiva: Dirce Maria F. Campos

\section{Conselho Consultivo}

César Zucco (UFSC)

Fernando Galembeck (UNICAMP)

Jailson Bittencourt de Andrade (UFBA)

Luiz Henrique Catalani (IQUSP)

Marília Fonseca Goulart (UFAL)

Paulo Cezar Vieira (UFSCar)

Vanderlan da Silva Bolzani (UNESP)

\section{Conselho Fiscal}

Titulares

Norberto Peporine Lopes (FCFRP-USP)

Sérgio de Paula Machado (UFRJ)

Roberto de Barros Faria (UFRJ)

\section{Suplentes}

Ricardo Bicca de Alencastro (UFRJ)

Fernando Antonio Santos Coelho (UNICAMP)

\section{Copyright (C) 2013 Sociedade Brasileira de Química}

Para publicação, requer-se que os manuscritos submetidos a esta revista não tenham sido publicados anteriormente e não sejam submetidos ou publicados simultaneamente em outro periódico. Ao submeter o manuscrito, os autores concordam que o copyright de seu artigo seja transferido à Sociedade Brasileira de Química (SBQ), se e quando o artigo for aceito para publicação.

O copyright abrange direitos exclusivos de reprodução e distribuição dos artigos, inclusive separatas, reproduções fotográficas, microfilmes ou quaisquer outras reproduções de natureza similar, inclusive traduções. Nenhuma parte desta publicação pode ser reproduzida, armazenada em bancos de dados ou transmitida sob qualquer forma ou meio, seja eletrônico, eletrostático, mecânico, por fotocopiagem, gravação, mídia magnética ou algum outro modo, sem permissão por escrito da detentora do copyright.

Embora todo esforço seja feito pela SBQ, Editores e Conselho Editorial para garantir que nenhum dado, opinião ou afirmativa errada ou enganosa apareçam nesta revista, deixa-se claro que o conteúdo dos artigos e propagandas aqui publicados são de responsabilidade, única e exclusiva, dos respectivos autores e anunciantes envolvidos. Consequentemente, a SBQ, o Conselho Editorial, os Editores e respectivos funcionários, diretores e agentes isentam-se, totalmente, de qualquer responsabilidade pelas conseqüências de quaisquer tais dados, opiniões ou afirmativas erradas ou enganosas.

Photocopying information for users in the USA. The Item-Fee Code for this publication indicates that authorization to photocopy items for internal or personal use is granted by the copyright holder for libraries and other users registered with the Copyright Clearance Center (CCC) Transactional Reporting Service, provided the stated fee for copying beyond that permitted by Section 107 and 108 of the United States Copyright Law is paid. The appropriate remittance of $\$ 6,00$ per copy per article is paid directly to the Copyright Clearance Center Inc., 222 Rosewood Drive, Danvers, MA 01923, U.S.A.

Permission for other use. The copyright owner's consent does not extend to copying for general distribution, for promotion, for creating new works, or for resale. Specific written permission must be obtained from the Publisher for such copying.

The Item-Fee Code for this publication is 0100-4042\$6.00+0.00

\section{Tiragem: 400 exemplares Circulação: Outubro/2013}

Editoração Eletrônica: Hermano - Tel.: (11) 5571-8937

Capa: Ana Paula Toscano - Tel.: (11) 9274-7523

Impressão: Margraf Editora e Indústria Gráfica - Tel.: (11) 4689-7100
Pedido de assinatura e distribuição

Secretaria da SBQ

Instituto de Química - USP

Av. Prof. Lineu Prestes, 748

Bloco 3 - superior

Tel.: (011) 3032-2299/Fax: (011) 3814-3602

E-mail: sbqsp@sbq.org.br

Apoio: 